\title{
Strategies for Improving Teachers' Information-based Teaching Quality in Vocational Colleges under the Background of New Industrial Revolution
}

\author{
Fengmei He ${ }^{1,2, *}$, Yihuai Chen ${ }^{1,3}$ \\ ${ }^{1}$ Department of Automation \& Electrical Engineering, Tianjin University of Technology and Education, \\ Tianjin 300222, China; \\ ${ }^{2}$ Institute of Information Technology, WenZhou Vocational College of Science and Technology (Wenzhou \\ Academy of Agricultural Sciences), Wenzhou, 325006, Zhejiang, China; \\ ${ }^{3}$ City University of Wenzhou, Wenzhou 325000, Zhejiang, China; \\ *Corresponding author.
}

\begin{abstract}
As "the fifth generation of educational revolution", the State Council and Ministry of Education have deployed and built a general environment for education informatization in 10 years. Vocational education cultivates information-literate high-quality technical talents, which is bound to require a promotion on teachers' information-based teaching literacy. Taking Zhejiang province's as an example, push forward from 5 aspects of "building platform, focusing on techniques, encouraging seminar, implementing educational reform, more integration"; conduct spiral progression means of "match-seminar-study-practice"; in allusion to information-based teaching literacy's concept, technical operation, resource application, design implementation, literacy transmission, assessment promotion, have a research on practical informational technology's rational application and methods to promote teachers' information-based teaching literacy, accelerate vocational education concept's innovation and development, provide high-quality talents for industrial transformation and upgrading.
\end{abstract}

Keywords: Information-based teaching, information-literate, information-based teaching literacy, Industrial digitization

\section{Introduction}

In the information age, the rapid development and application of information technologies such as internet plus, cloud learning, big data, blockchain, and artificial intelligence are changing the demand for talents and the form of education. With the education of technological empowerment, mobile learning, ubiquitous learning and intelligent education have emerged. To realize the three-step strategy of "Made in China 2025", high-quality skilled personnel with information literacy are urgently needed. In May 2012, Opinions of the Ministry of Education on Accelerating the Development of Vocational Education Informatization proposed that vocational education can improve the quality and efficiency of personnel training through the effective application of information technology in classroom teaching. In February 2019, the CPC Central Committee and the State Council issued China's Education Modernization 2035, which proposed "accelerating the educational reform in the information age. Build an intelligent campus and make overall plans to build an integrated intelligent teaching, management and service platform. Use modern technology to accelerate the reform of personnel training mode and realize the organic combination of large-scale education and personalized training. Innovate the educational service format, establish a sharing mechanism of digital educational resources, and improve the benefit distribution mechanism, intellectual property protection system and new educational service supervision system. Promote the reform of educational governance methods, accelerate the formation of a modern education management and monitoring system, and promote accurate management and scientific decision-making."[1] In recent ten years, China has continuously constructed the environment of educational informatization, promoted the development concept of educational informatization, and guided the development direction of educational informatization of schools, teachers and educational service institutions. Vocational education is different from general education in that it is professional, social, practical, popular and lifelong. To stimulate the needs of teachers' education informatization in vocational

ISSN: 0010-8189

(C) CONVERTER 2020

www.converter-magazine.info 
colleges and improve the information-based teaching quality is an important link to promote the development of vocational education informatization, and also a prerequisite for cultivating high-quality skilled talents' information-based quality.

\section{The Structure of Teachers' Information-based Teaching Quality}

In 1974, Paul.Zurkowski, Head of the United States Information Technology Office, proposed that "information literacy is the technology and skill to solve problems by using a large number of information tools and their main information resources." [2] The American Library Association (ALA) gave a definition in 1989: "A person with information literacy must be able to fully understand when information is needed and be able to effectively discover, retrieve, evaluate and use the information needed." [2] In 2010, Zhong Zhixian pointed out that "information literacy refers to the ability to use various information tools, especially multimedia and network technology tools to identify, find, evaluate, organize and effectively produce, use and exchange information to solve problems." [3]

With the development of information literacy in various fields, information literacy and specialty are integrated in the working environment, which provides ideas and reference for vocational education to train high-quality skilled personnel with information literacy. In 2018, Yan Xianzhuo proposed the transfer of information literacy from academic environment to workplace environment [2] to guide teachers' instructional design and individual learning to the workplace, realize students' recognition of legal knowledge types and information sources in the workplace, and promote their professional ability and professional quality.

Teachers in vocational colleges need to face different majors, different disciplines and different work scenes. Zhu Zhiting divides teachers' information literacy into four levels, namely basic information literacy, subject information literacy, special information literacy and scientific research information literacy.

"Information-based teaching quality" is a general term for teachers' knowledge, ability and attitude to realize the effective integration of information technology and classroom teaching.

The level of teachers' information-based teaching quality directly affects the cultivation and improvement of students' information literacy. In the teaching material Consciousness of Information-based Teaching prepared and developed by the Training Special Committee (to be established) of the Vocational College Information Teaching Steering Committee of the Ministry of Education, the six dimensions of teachers' information-based teaching ability are described in details, including information-based teaching ability, course organization and evaluation ability, ability to apply teaching methods, ability to apply technology and equipment, classroom teaching and management ability, learning and professional development ability. [4]

The information-based teaching literacy in this paper refers to (including the ability to apply information-based literacy and the ability to educate information-based literacy): the ability to serve professional learning and the overall design of courses, with the awareness and ability of informatization, to effectively apply information technology, appropriate teaching methods and integrated teaching styles, and to transfer learning methods, knowledge, skills and information literacy to professional learners, so as to achieve the co-construction of teaching information software and hardware. From the perspective of professional learning in vocational colleges, whether the application of information-based teaching can arouse students' enthusiasm to achieve the best learning effect, and whether it can promote students' ability to use information-based means to carry out professional independent inquiry learning, evaluation and effective utilization.

In order to cultivate professional students' information literacy, teachers in vocational colleges need to have six dimensions of information-based teaching literacy (as shown in Fig. 1). 


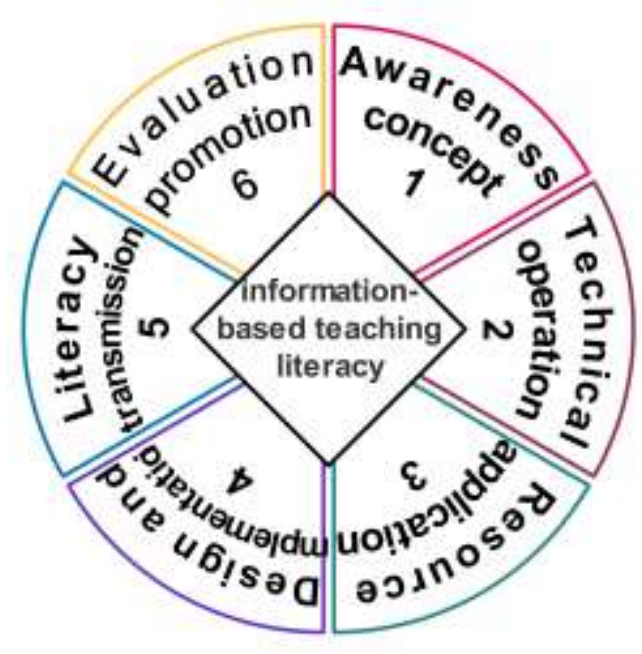

1.Awareness concept: with information awareness, application ability, ethics and sustainable development of learning methods

2. Technical operation: with information technology knowedge, technical skills and product operation ability

3.Resource application: with the ability to acquire, use, design and evaluate teaching resources

4.Design and implementation: with the ability to design, organize, manage and evaluate teaching content and teaching process

5.Literacy transmission: with knowledge and skills teaching ability and information literacy education ability

6.Evaluation promotion: with the ability to evaluate and improve students' information literacy

Fi. 1: Six dimensions of information-based teaching literacy

1. Awareness concept: with information awareness, application ability, ethics and sustainable development of learning methods. Deeply understand the reform policy of educational informatization, update the teaching concept, content and method, and explore the online and offline mixed information literacy cultivation. Actively study, think and reasonably apply the information-based instructional design concept, and recognize that the integration of information-based teaching concept and specialty has a positive effect on the classroom teaching effect and professional development of Vocational education.

2. Technical operation: with information technology knowledge, technical skills and product operation ability. Master the operation skills of common software, network and digital media, actively explore and promote intelligent learning platform and space application of new technologies such as artificial intelligence. Reasonably apply information technology and equipment facilities to solve problems in teaching, learning and working processes, and make effective monitoring and management.

3. Resource application: with the ability to acquire, use, design and evaluate teaching resources. As the teaching in vocational education cannot show a complete working scene, simulation is generally adopted to realize the working process and content, especially digital media which has advantages in realizing the teaching, learning process and working process. Evaluate teaching resources according to specific teaching needs, select appropriate teaching resources from national, provincial, municipal, school and third-party teaching service platforms, and realize the reorganization of teaching materials, teaching resources and learning content through further processing and design, and apply them to the teaching process reasonably, so as to improve teaching efficiency.

4. Design and implementation: with the ability to design, organize, manage and evaluate teaching content and teaching process. To be able to use information technology accurately and effectively, design teaching content and process that meet the characteristics of professional learning, create a learning environment, use appropriate teaching methods to carry out teaching activities, continuously monitor students' learning situation and collect learning data, effectively evaluate students' learning effect, improve classroom teaching effectiveness, and guide students to gradually realize in-depth learning of vocational skills.

5. Literacy transmission: with knowledge and skills teaching ability and information literacy education ability. Teach students professional knowledge, skills and learning methods. Cultivate students' information literacy abilities such as information awareness, information technology skills, information security awareness, vocational skills integration informatization and information innovation. Realize self-determination of where and when to choose the most suitable resources for learning.

ISSN: 0010-8189 
6. Evaluation promotion: with the ability to evaluate and improve students' information literacy. Follow the development of the times to explore professional learning paths, deeply understand the information environment of professional workplaces, integrate professional information skills into teaching, and carry out the evaluation of information literacy ability, so that students can constantly pay attention to the improvement of self-ability in any new working environment, so as to meet the changing work requirements and realize the sustainable development of students' professional ability and professional core literacy.

To cultivate students' information literacy, it is necessary not only to rely on general courses such as computer foundation, but also to integrate information literacy education into all courses, especially professional courses in an all-round, diversified, hierarchical and targeted way.

\section{Current Situation of Teachers' Information-based Teaching Quality in Vocational Colleges}

With the improvement of educational informatization, it is possible to improve the informatization teaching quality of teachers in vocational colleges. However, due to the fact that education informatization is not endogenous at present, most teachers have basic ability to apply information technology, but they are satisfied with the present situation and lack the motivation and pressure of reform, which leads to the insufficient innovative ability of information-based teaching and the lack of thinking and practice of technology empowerment education.

\subsection{The concept of awareness-deviated concept of information-based teaching}

Due to the deviation of understanding caused by the fact that teachers' information-based teaching stays in a relatively intuitive and low-level application, it is difficult to build an education system that is commensurate with the level of technological development of the times and to realize a qualitative leap in educational information, especially in the field of vocational education. Common misconceptions are reflected in the fact that online courses are the online courses of traditional courses, i.e. the offline classrooms are turned to live or on-demand classrooms; the more information technology is applied, the better it will be; education information is the diversity of information technology means, ignoring the needs of specific teaching content; emphasizing the concept of instrumentality, integrating information technology and education from the perspective of the application of technological tools, entering the vicious circle of technological application; overuse of the courseware that PPT courseware is used for the whole class or the whole course, changing from "inspiration" to "clicker" and being led by PPT. For example, during the epidemic, the PPT "click" teaching was directly transferred to the live broadcast platform. Teachers had no awareness and ability to develop information resources, and many of them were accidental in the application of relevant tools, lacking overall planning and top-level design. Information resources were directly distributed to students to carry out independent inquiry learning without corresponding guidance design and acceptance in the teaching stage. The information teaching competitions were hollow words, which was separated from the teaching practice and has no practical significance.

A clear analysis of the concept of consciousness makes it clear that no advanced educational technology can automatically improve the teaching effect. Information resources are mainly used to supplement face-to-face teaching and improve the efficiency, especially the introduction, preview, demonstration and review of practical courses can be made use of information technology, which is more convenient, quick and understandable, and can guide teachers' information-based teaching, which is verified by practical teaching and students' learning effect.

\subsection{Technical operation- Insufficient motivation to explore the rational application of new techniques}

Information technology covers the operating capabilities of hardware and software. Hardware includes computers, smart phones and ancillary information equipment. Software includes office software, audio and video editing software, online communication platform, network teaching platform, professional related virtual simulation software, etc. Many teachers have the basic operation ability for the application of hardware and various kinds of

ISSN: 0010-8189 
information-based teaching software, but lack the ability to find and reasonably use the new techniques for their major or course and the ability to reasonably select information-based teaching tools.

Information technology provides an intuitive interactive learning environment that also attracts some teachers, but focuses on the presentation of information technology means, resulting in excessive use of technology, which puts the cart before the horse and fetters the teaching.

Computer teachers have inherent advantages, such as information knowledge, technical skills and product operation ability, as well as operation skills of commonly used software, network and digital media. Non-computer teachers are unable to skillfully apply information technology due to their mastery of certain information technology skills and basic operation ability of information technology and equipment and facilities. Instead, they mostly present information-based teaching contents. Moreover, many teachers are still at the exploratory stage for the application of new technology and how to solve the problems in teaching, learning and working process. Especially they have not effectively monitored and managed the application and are more involved in assisting the transfer of knowledge and skills. Computer teachers have an insignificant position in advancing educational informatization, and are self-administered and develop autonomously during the whole process. Besides, it is rare for computer teachers and non-computer teachers to mutually explore, learn, and communicate the reasonable support of the new technology for teaching, and the same is true between teachers in the same major.

\subsection{Resource application - usual practice of copy}

Teaching resources include teaching materials, courseware, e-books, special websites, learning packages, national standard database, case database, etc.

From the perspective of construction, the development of information construction is not balanced. Moreover, the construction of teaching resources is in a state of "attaching importance to construction but neglecting utilization", with insufficient promotion and later support. The identification and application of high-quality teaching resources are less realized in integration and common use, and their utilization rate is low.

From a practical point of view: teaching resources are more accustomed to use, which is manifested in the direct use of teaching resources obtained from each platform, and cannot be modified twice according to their own teaching needs. In particular, the teaching resources of textbooks are not reorganized according to the teaching objects and teaching contents, so the application of resources is inappropriate. Mooc takes the place of teachers to teach, which lacks the process of answering questions and the consideration of teaching efficiency.

\subsection{Design and implementation-lack of awareness of breaking through teaching materials}

Many teachers start teaching based on the modules and supporting teaching resources of teaching materials, lacking the awareness of breaking through teaching materials. Moreover, they don't realize that the focus of vocational education informatization design is on concepts, skills, instructional design and teaching implementation. Moreover, they fail to realize that the focus of the information design of vocational education is on concepts, skills, instructional design and teaching implementation, but pay too much attention to means while neglecting students' learning situation, teaching content, teaching resources and learning methods themselves, which results in the lack of practical application of information-based teaching effectiveness evaluation in teaching. Online interactive instructional design is still not common, and it does not bring wonderful online interactive instructional design to inspire students to think deeply, which leads to poor teaching effect of online courses. Without detailed analysis and assessment of the students' learning data, or consideration of the in-depth learning mode and path of the professional skills of the major or the course, students have no unique experience in the learning process of knowledge and skills.

\subsection{Literacy transmission-lack of awareness of transmission}


Although teachers have information literacy, they do not attach importance to information literacy education. However, the key usage of information-based teaching should be practiced in teaching. In the teaching process, teachers pay more attention to the teaching of knowledge and skills, and the information literacy education involved is basically achieved by arranging students to search via Baidu, without specific case guidance analysis and related expansion practice, etc., especially without teaching students to keep sober and do a good job in selection. The effect in meeting the improvement of vocational ability and professional core literacy is not obvious due to the lack of learning initiative, the high demand and attention for the use of network and mobile phones, and the lack of correct and reliable guidance scheme and excitation path for how to reasonably and harmoniously use the information resources and platforms of vocational college students

\subsection{Evaluation promotion-ignoring the evaluation of information literacy}

Students' evaluation focuses on summative evaluation, rather than evaluation of learning process and improvement of information literacy ability. The evaluation of improving students' information literacy is not integrated into the professional work field, does not involve the evaluation of obvious ability, and the evaluation standard of improving students' information literacy is not clear and uniform. Teachers' neglect of information literacy evaluation will cause most students to neglect or pay no attention to the improvement of information literacy, which can not meet the changing job requirements.

In education informatization, external force is needed to promote change and improvement. It is necessary to establish the concept of information technology to promote vocational education, to drive teachers to improve their information-based teaching quality, to apply information-based teaching technology rationally, so as to improve students' information quality and to become high-quality skilled talents.

\section{Strategies for Improving Teachers' Information-based Teaching Quality in Vocational Colleges}

The "concretization of abstract problems, simplification of complex problems, application of theoretical problems and working of learning process" can be achieved through construction in practice, promotion in discussion and integration in thinking[5], by means of effective integration of information technology, the transfer of professional learning methods, knowledge and skills, to promote students to consciously use information means for improving their abilities of professional independent inquiry learning, evaluation and effective use, mobilize the enthusiasm of students to achieve the best learning effect, cultivate students to become a "information man" with information literacy, to play the advantages of information-based teaching in the service of individual, personalized and lifelong learning.[6]

In this paper, efforts are made from five aspects: "building a platform, emphasizing skills, promoting research, practicing teaching reform, and multi-integration" by studying teachers of 75 technical colleges in Zhejiang Province (including teachers of basic courses and specialized courses). Since 2015, the teaching and research group of the Computer Center of Zhejiang Vocational Skills Teaching Institute has launched an information-based instructional design competition year by year, with participants expanding from the initial computer professional teachers to all basic and professional teachers, in the form of evolution from offline to online and to online and offline combination", trying to take the competition as an opportunity to provide a learning exchange mechanism. The application of information technology is carried out in a "competition-discussion-learning-practice" spiral progressive way (as shown in Fig. 2) to study and practice the rational application of information technology and improve teachers' information teaching literacy, strengthen teachers' information teaching literacy in six dimensions: information awareness concept, technical operation, resource application, design implementation, literacy transmission and evaluation, accelerate the innovation and development of vocational education concepts, and effectively realize the improvement of teachers' information teaching literacy in vocational colleges. 


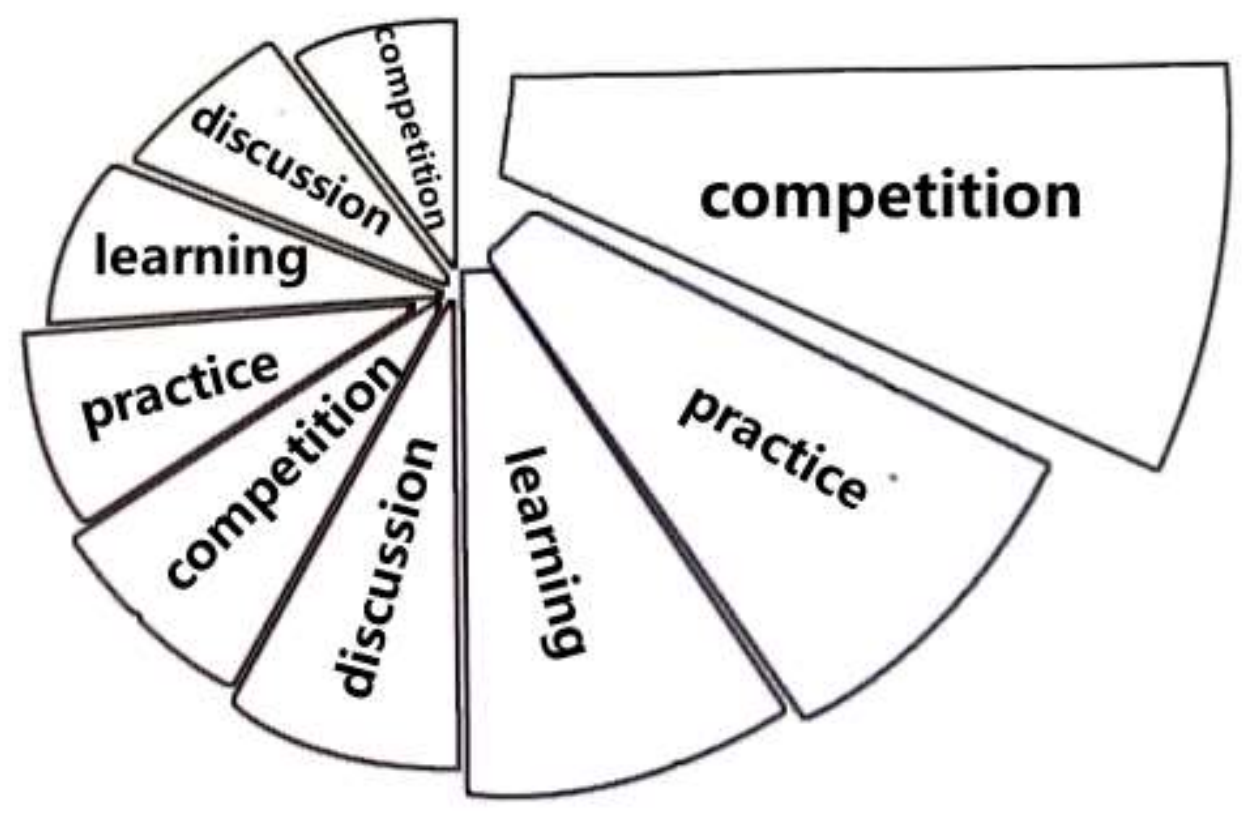

Fi. 2: Spiral progressive mode

4.1 Platform building: Building a competition platform to promote multi-party cooperation and development

Competition is an effective way to rapidly promote information concept, technique, instructional design, etc., which can realize the discussion, study and promotion among players, schools and majors. Based on the implementation idea of "from simple to difficult and from point to surface", three stages are designed, namely, warm-up, information application and on-line and off-line blended teaching (as shown in Table 1). According to the characteristics of short and pithy micro-courses and the continuity of the competition, micro-courses are used as the carrier in the early stage and the mixed practice of online platform and micro-courses in the later stage, which not only avoids teachers' misunderstanding that educational informatization is micro-courses, but also realizes the deep integration of information technology and classroom teaching, integrating instructional design competition with real teaching classroom, improving and testing teachers' information-based teaching ability and teaching literacy, and at the same time prompting teachers to actively think and design the guidance and transmission of information literacy. The six dimensions of teachers' teaching information literacy have also been improved with the iteration of competition patterns and requirements.

Table 1 Details of competition practice

\begin{tabular}{|c|c|c|c|c|c|c|}
\hline Stages & Years & Objects & Coverage & Carrier & Forms & Objectives \\
\hline Warm-up & 2015 & $\begin{array}{l}\text { Individual } \\
\text { competition: } \\
\text { computer } \\
\text { teachers }\end{array}$ & & \multirow[t]{2}{*}{ Micro-courses } & $\begin{array}{c}\text { Live } \\
\text { competition } \\
(55 \%): 4 \text { hours, } \\
\text { heterogeneous } \\
\text { forms for the } \\
\text { same subject } \\
\text { Off-site } \\
\text { competition } \\
(45 \%) \text { : selecting } \\
\text { topics for } \\
\text { discussion and } \\
\text { submitting } \\
\text { works for } \\
\text { micro-courses }\end{array}$ & $\begin{array}{l}\text { To promote the } \\
\text { information } \\
\text { application level } \\
\text { of computer } \\
\text { teachers in } \\
\text { technical colleges } \\
\text { in the province, } \\
\text { and to release the } \\
\text { signal for the } \\
\text { trend of } \\
\text { information } \\
\text { application }\end{array}$ \\
\hline $\begin{array}{c}\text { Application of } \\
\text { information-based } \\
\text { teaching }\end{array}$ & 2016 & $\begin{array}{c}\text { Team } \\
\text { competition: } \\
\text { professional }\end{array}$ & $\begin{array}{l}\S \text { Basic group (computer } \\
\text { foundation, Chinese, } \\
\text { mathematics, English); }\end{array}$ & & $\begin{array}{l}\text { Preliminary } \\
\text { competition: } \\
\text { submission of }\end{array}$ & $\begin{array}{l}\text { To enhance the } \\
\text { scope of } \\
\text { participating }\end{array}$ \\
\hline
\end{tabular}

ISSN: 0010-8189

(C) CONVERTER 2020

www.converter-magazine.info 


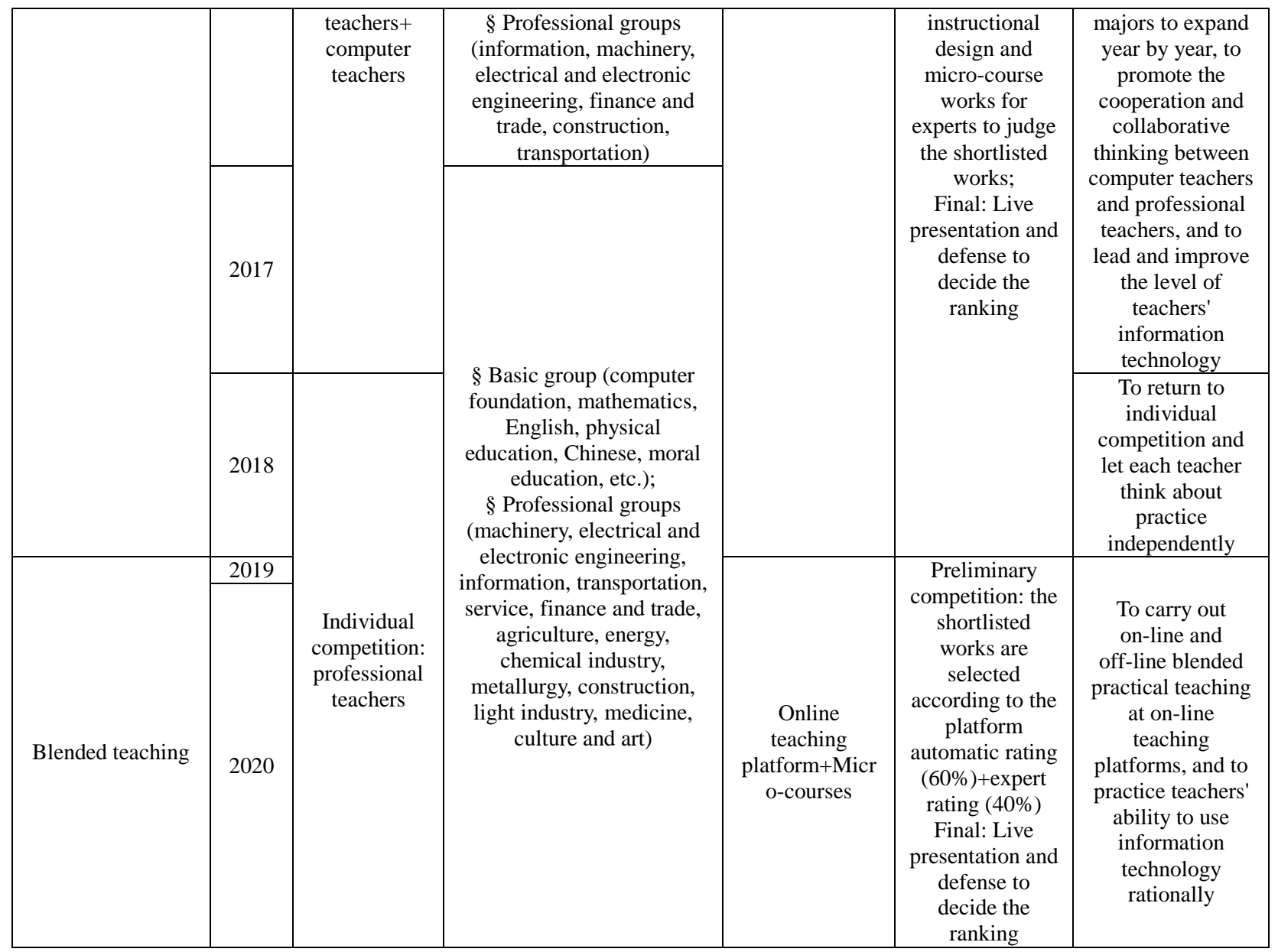

It is necessary to deeply study the position of computer teachers in promoting educational informatization, because they are an important group to build and promote educational informatization, which can help professional teachers solve the problem of optimizing the application of information technology in the classroom, promote the application of modern information technology in teaching, and support the implementation of educational informatization. Through the cooperation between professional teachers and computer teachers, the focus is on "the deep application of information technology in professional teaching", "the effect of moderate application of information technology", "which knowledge point will be better than the original teaching method" and so on, so as to strengthen the deep integration of computer teachers and professional teachers, learn together in the process of cooperation and continuously feel the influence of information technology, and motivate professional teachers to apply information to carry out teaching, improve the ability and level of information application design, and constantly improve the six dimensions of information teaching literacy under the development of new technology, combine the curriculum teaching reform with the application of information technology, and try to optimize the teaching, so as to realize the training of innovative talents in vocational education.

The competition can promote the in-depth integration of information technology, equipment and education and teaching, explore and research new teaching modes, realize integration and innovation, and promote teachers to explore, try and think about the application of information technology, so that they are willing to devote more energy to work out a good curriculum design, and think about the problems and solutions in the application of technology, realize the integration of information technology and professional courses, and effectively infiltrate information technology into professional course teaching.[7]

4.2 Emphasis on skills: Focusing on vocational skills and building and sharing high-quality resources

ISSN: 0010-8189 
Teaching and learning in vocational colleges focus on the application of skills, involving a wide range of majors, so the skills practice teaching resources are in urgent need of high-quality resources. Efforts should be made to realize the construction concept of "promoting construction by and focusing on application" of vocational education information resources, focusing on the construction of training resources and "pain points" teaching resources, and to build a platform to realize the joint construction and sharing of the use of high-quality resources.

The competition materials and excellent works should be summarized into digital teaching resources, which are shared in the form of examples for more teachers to use, so that they can understand how the innovative attempts of information teaching penetrate into professional curriculum design, content transmission, classroom activities, auxiliary learning before and after class, etc., enhance their teaching demands for the application of information technology, gradually improve the teaching ability of information processing and communication, explore the use of information technology to transform traditional teaching, achieve a breakthrough in teaching quality, and provide reference for subsequent competitions or daily information attempts.

Among the teaching resources, teachers need to guide students to establish correct concepts of network time and space, ethics and information awareness; information-based teaching enables students to experience more intuitive, improve interest in learning through the creation of simulation scenarios, which is conducive to promoting exchanges between teachers and students, especially enabling every student has the right to speak; the blended practice teaching of online platform + micro-course can enable students to start learning at any time and place with the leaning contents available for review at the platform in the future work when needed.

Some teachers feel that the competition is too time-consuming and unwilling to participate, but all teachers must face and practice the improvement of information-based teaching quality, because the co-construction and sharing of high-quality resources will also make them realize the trend of information-based teaching, gradually change their teaching thinking and consciousness, and improve their information-based teaching quality.

\subsection{Promoting seminars: Setting up multi-form seminars to promote application of informatization}

Information-based teaching competition is designed to examine teachers' ability to use information technology, digital resources and information-based teaching environment reasonably and solve teaching difficulties, discuss the design purpose, implementation effect, and production methods, software and toolkits of micro-lesson videos. The application and actual effect of information technology in the micro-class teaching process can be specifically analyzed as "what is a certain information technology point, which knowledge point it is used in, why this technology point is used for processing, and what effect is achieved", etc.

With the goal of high-quality entries, discussions and elaborations within the professional groups of teachers should be made in all colleges and universities so as to construct a high-level instructional design and attract attention to the application of information technology from point to surface. At the same time, according to the results of the information application instructional design competition, the excellent works should be demonstrated and reviewed, and the process of deconstructing knowledge points by information technology is expounded based on cases, which is convenient for everyone to learn horizontally and realize mutual learning among participating teachers.

4.4 Practicing the teaching reform: Practicing the guidance of open courses and analyzing excellent achievements in depth

In order to avoid the phenomenon of competition only for competition, information-based teaching, teaching seminars and other activities should be carried out in the form of open classes to practice the idea of excellent instructional design. In order to solve the problem of disjointed and uncoordinated competition and actual teaching, it is necessary to choose the excellent instructional design of the first and second prizes, set up open courses in provincial and municipal teaching and research activities, and further discuss and promote the application in the form of course evaluation. Through the evaluation of the six dimensions of information teaching form, instructional design and the subjective efficiency of teachers and students, teachers' information literacy, the information application

ISSN: 0010-8189 
instructional design is studied and discussed from outside to inside, from theory to practice, from design to landing to improve the means of information technology service classroom teaching, in order to achieve the qualitative leap of education information and solve the painful problems existing in the teaching process of vocational education. For example, the excellent instructional design of the team competition is displayed and discussed through the open class of "one lesson and two teachers", that is, a lesson is prepared and taught by a professional teacher and a computer teacher together for discussing information technology to solve and deal with knowledge points, classroom teaching, pre-class and after-class auxiliary teaching, etc. In this way, with the help of computer teachers, the information-based teaching quality of professional teachers can be improved from trial to application.

4.5 Multi-integration: Multi-party integration and intercommunication to establish a cross-border community of educational informatization in vocational colleges

A community composed of government, enterprises, third-party online education platforms and universities should be established to achieve the win-win model needed by each from the aspects of directional construction, industrial structure adjustment, theoretical research and information-based personnel training.

In the blended teaching stage, the online platform of vocational education service should be introduced to automatically score, so as to realize online and offline teaching of information technology application and generate scores and corresponding rankings. The micro-course works designed and produced should be put on the cloud online teaching platform, and integrated into the real teaching before class, during class, after class and student evaluation, so as to enhance teachers' awareness and ability of using information technology to carry out online teaching. On the spot, the teaching courses on the online platform, online and offline teaching design and reflection (including teaching content, teacher-student interaction, information literacy transmission, etc.) should be displayed and analyzed. The authenticity of online quantitative evaluation improves the teaching and learning level of teachers and students. Preview review can be evaluated not only through online learning, but also through questions and interactive activities, which reasonably quantifies teachers' workload before, during and after teaching, such as making micro-courses, uploading materials, preparing exercises, and interacting with students in and out of class, thus enhancing teachers' enthusiasm and creativity.

After many years of practice, the enthusiasm of teachers, the quality of their works and the fields of their works have been greatly improved. They tend to keep improving from the aspects of topic selection, teaching design, production level and the comprehensive quality of the contestants. In particular, the selection of the subject focuses on the production line, which not only reflects the daily teaching guidance but also takes into account the needs of the real scene of the enterprise, and is suitable for the characteristics of vocational college students. Moreover, they understand and apply information technology in place, have the spirit of thinking and innovation, realize the deep integration of information technology and curriculum design, and skillfully apply various tools and internet teaching platforms.

However, there is still a large gap in the research, updating and application guidance of teachers' educational concepts, modes, contents and methods among cities, schools and teachers. In particular, professional courses vary greatly. Thus, it is necessary to deeply understand the technology, platform, resources, etc., to achieve the normalization of technology application, form a reasonable use of technology platform resources, improve the teaching ability of information data processing and significance communication, and truly achieve the teaching of technology empowerment. In the future, people's way of life will change from feeling to perception, from perception to control, which will promote and change many aspects of information-based teaching. Therefore, there are still some problems to be solved, such as scientifically regulating and guiding students to use electronic products; breaking the traditional teaching time and reasonably arranging the online teaching time; integrating the teaching content into three modules of students' self-study +teachers' teaching +AI teaching so as to more reasonably drive the improvement of information-based teaching quality; incorporating information-based teaching application and teaching evaluation into the professional course standards of vocational colleges; preparing the courses from diversification, synthesis, building blocks and modules; and establishing an industry, enterprise participation

ISSN: 0010-8189 
mechanism, so that they can obtain the corresponding social benefit or economic benefit in the cooperation, do a win-win situation of school-enterprise integration, etc.

\section{Conclusions}

The teachers' information-based teaching quality can be improved by not only external promotion but also endogenous development. Information-based teaching cannot be limited to fixed patterns and fixed technologies, otherwise it will lose the characteristics of information. It is necessary to truly realize the technical empowerment to educate teachers, which plays an indispensable role in improving their information-based teaching quality. The informatization of education does not deny traditional teaching. In order to realize the efficient teaching of traditional knowledge, it is necessary to realize the cultivation of comprehensive literacy and lifelong education in modern learning, and provide personalized education services for each learner through educational informatization to improve learners' learning effect. We should have a forward-looking vision in the construction of vocational educational informatization, and consider the sustainability in the application of informatization, so as to realize the informatization of vocational education and promote the modernization of vocational education.

\section{Acknowledgement}

The paper was supported by Program of Zhejiang Institute for Vocational and Technical Education: "Practice and Study of the Improvement of Teachers' Information-based Teaching Competency in Technical Institutions of Zhejiang Province in the Educational Information Era" (201702051) as the research achievement of Wenzhou "Assistance of Workers and Peasants" (2017) activity and Research Program dealing with underdeveloped areas: "Research on the Improvement of the Teaching Design Ability of Vocational Teachers under the Background of Intelligent Education" (No. 12).

\section{References}

[1] China Education Modernization 2035 issued by the Central Committee of the CPC and the State Council. February 2019.

[2] D. Wu, X.Y. Li, S. Xu, J. Dong, S. Fan, D.Y. Gui. Use and development of information literacy theory in recent ten years. Library Journal, vol. 39, no. 1, pp. 26-35, 2020.

[3] Z.X. Zhong, F.W. Wang. "Web2.0 Learning culture and information literacy 2.0," Journal of Distance Education, vol. 8, pp. 34-40, 2010.

[4] C.B. Xie. "Information-based teaching awareness," Beijing: Higher Education Press, 2016

[5] Z. Wang. "Design and implementation of modern vocational education teaching information technology," Vocational \& Technical Education Forum, vo. 30, pp. 72-75, 2014.

[6] S.H. Guo. "Introduction to information literacy research in library and information science," Journal of Information, vol. 7, pp. 26-28, 2003.

[7] Q. Xia, M. Cao, S.S. Shen. "Effective ways for information-based tools to enter teaching," Modern Educational Technology, vol. 27, no. 7, pp. 61-67, 2017. 